\title{
On the Factors Affecting the Basketball Referee Level of College Students and the Countermeasures
}

\author{
Chunxia Yang \\ Yunnan College of Tourism Vocation, Kunming, Yunnan 650106
}

Keywords: College students; Basketball refereeing level; Factors; Strategy

\begin{abstract}
. level of education in high school has been raised gradually in recent years, and as the one of important stages of our educational career, high-school education plays great role in development of students, it also a teaching stage to output trained people for society, therefore, it gains most attentions from all of walls and educationists. Different with other time, education in today emphasizes comprehensive development of students, as it develops teaching activities, sports education career will be an essential part of it that affects students largely and be a major measure strengthening their body. Sports like basketball, is a reflection of competition and hot blood that be popular by people from every age, there is no special among high-school students group. While students playing basketball, they are influenced by kinds of factors and the level of refereeing standard that will not only affect the fairness and equality of basketball activity, but popularity and development among high-school students, it plays great influence for students and how to up the refereeing level has became a key factor in development of high-school basketball. Therefore, this article is targeted at the factors influencing refereeing standard in high-school basketball and states the concrete solution about it, hoping it will bring positive affect to development of high-school basketball activity.

As for students majoring in sports, basketball item is an essential activity that emphasize on antagonism in the same field training, and as a competitive sports, it realizes transition that from offense to defend through body contacting between players. In high school, it is the referees that decide the direction of judgment in basketball field, however there are several errors in judgment including a. false negatives; b. misjudge; c. disorderly judgment that will affect the actual result of basketball tracks to different refereeing quality or outside factor. The impact of basketball referees made in high-school basketball activity, and the actual ability in temporary refereeing will be the main factor to influence the level of referees. While playing basketball, most high school students will put their energy in trainings of technology and strategy, there are little learning content about basketball refereeing which will lead to a weak refereeing ability and less attention from students to refereeing level improving. Referees as college students have less practice time than other items and the whole level of basketball refereeing need to be improved.
\end{abstract}

\section{The Subjects of this Study and the Measurement Applying}

The Subjects of this Study. In order to assure accuracy of this study result, we set the standard rage among a group of students from a university majoring sports, and chose students those tool basketball to be the subjects.

Method Applied in this Stud. In this research, there are main methods applied as following. First is questionnaire, it needs to design and the hand out to theses test these picked students who are high-school basketball referees, and then collect finished questionnaire. Next one is literature review, it needs to looking through related academic website and refer to massive books and papers about basketball refereeing law and rules, summing up central meaning of related papers, making collation and induction, comparing the subjects with summary of related content about basketball refereeing. Then is interview with experts, it needs to interview experts in related organization that regulate basketball activity in this city and scholars as well, taking communication and interview and investigate deeper into the groups of managers doing high-school basketball refereeing task, and catch up the present developing situation and each issue existing in high-school basketball refereeing ${ }^{[1]}$. Apart from these, it also needs to do related statistic work after collecting 
questionnaire, there will be a clear statistic because of checking reference and taking material in form of cultural and educational investigation, interviewing experts as well, therefore, a line chart basing on it will show obvious transformed situation of data and part of them with actual ratio will present. And last, the logic analysis, such method aims to paper writing and material studying, and then takes comprehensive application of measures like analogism, comparative research, inductive deductive method and comprehensive analysis and so on.

\section{The Factors that Influence Level of Basketball Refereeing}

Personal Quality of a Referee. Since college students show great passion to basketball, while playing basketball, they are also interested in refereeing, personal quality is main factor to the level of basketball referees, and besides of it, the referees should have a certain professional ethics, devoting themselves into development of basketball career. They should obey the rules of basketball matches basing on respecting facts, improving law enforcement, and thus achieve judgment.

Temporary Refereeing Ability is Affected by Level of Professional Quality. If basketball referees want to play an important role in college basketball activity, they should have enough knowledge of basketball refereeing law and rule, however, according to present developing situation of high-school students' basketball refereeing, there has much to do with basic theory of basketball, and because some basketball referees lack deeper knowledge of rules that could not make reasonable judgment to actual technologic level and thus lose reasonable, their temporary refereeing will not promote as well. Apart from it, in temporary refereeing, basketball referees usually judge by gesture that could convey the basic information, and assure every item will go ahead smoothly ${ }^{[2]}$. Referee needs to convey standard gestures to players, which is the key factor that will influence the refereeing level. Besides, if referees want to assure the coherence of basketball match, they should grasp the characteristics of it while refereeing, and follow rules, trying to take law enforcement scale in a reasonable range. However, some referees feel difficult to hole the rule and thus influence the refereeing results.

Lack of Sound Refereeing Mental Quality. While refereeing in basketball activity, referees should base their strong confidence on it and thus they will control mood in temporary refereeing, doing reasonable judgment. And they could calm down when facing sudden event, taking effect measurement to solve out. Referees should have determination and quick wit, however, after investigation, we found that part of college referees are easily influenced by mood while doing temporary refereeing, it not only presents as excessive emotional but physical strength that hard to adapt high intense basketball activity ${ }^{[3]}$. Referees often reveal expression like hesitate, nervous or at a loss while they pronounce results, which will influence seriously the final result. Besides, physical quality also matters. According to the investigation, the level of college student as basketball referees are influenced deeply by it, there over 30 percent has been impacted totally, $20 \%$ is influenced partly, which means that only around $10 \%$ students will independent on physical quality. According to it, improving physical quality is a key point to temporary refereeing for college students, and it needs to more attention ${ }^{[4]}$.

\section{Related Measurement to Improve Level of Basketball Refereeing}

To Emphasize on Basic Theory Learning. If we want to assure the level of temporary refereeing will be improved greatly, being calamity while refereeing and could solve out accidents with effect, it is important to grasp and master each rule of basketball refereeing law. They need to strengthen the basic knowledge, learning basketball refereeing rules and match rules, being familiar with each technology and strategy and recognize unfair play and break-rule movements which then make precise judgment ${ }^{[5]}$. Besides, basketball referees also need to strengthen the basic training, mastering needed gestures that will be applied while refereeing, and thus could build a coherent, effect and timely communication with player in match field. Therefore, referees could take gesture training by themselves and blow the whistle with comprehensive and systematic, they could do correct training about gesture with help of others. When taking training as blowing the whistle, they 
should do inhalation and suffocation, and then take quick blow, upper and down lip should bite the whistle tightly. It needs quickly and shortly, the prime thing for referees in temporary refereeing is brain ability, next is physical strength, thus brain of a referee should react quickly that could catch up the pace of match process. Therefore, in daily training, they could apply visual signal that body can quick move by it. Apart from this, a referee should take basic moving training which including: a. run and shift direction; b. glade; c. side running; d. turn observation; e. start moving; f. crossing steps. In specific basketball activity, referees should make corresponding adjustment in temporary refereeing, according to the moving method from basketball players ${ }^{[6]}$.

To Take Right Attitude in Temporary Refereeing. If basketball referees want to improve their temporary refereeing level with effect, they should take the right attitude towards it, which means they should obey the law while working and strengthen their own professional ethic, avoiding the happen of abuse the authority and rights they gain from the public ${ }^{[7]}$. In actual basketball matches, referees should solve every emergence situation in match field with their personal quality, following professional ethic and match rules which will assure the match goes ahead with fair and public. They should devote into development of basketball career, showing their own value with it ${ }^{[8]}$.

To Assure the Goal and Spirit of Temporary Refereeing. In basketball activity, referees are the only law executor while two teams compete with each other. The purpose of refereeing is to push the match with fairness and order, and referees need to clear the real purpose of temporary refereeing ${ }^{[9]}$. Insides the heart of referees, they should posses with spirit of temporary refereeing, and could take effect control of the match, making sure the integrity of match content and fluency of procedure, showing the visual value of basketball match and affect every attendant with basketball spirit. They should assure the rule and intention of basketball match and be strict with the movements that should not exist, to the actions which could take with slow half step, they need to be fair as well, for example, once players interfere the shooting action or breaking rule in three-seconds zone which they need to do penalty shot, however, referees should normalize every item of match ${ }^{[10]}$. Referees should adjust each rule with effect and follow the demand of it, completing the action normalization, and bring positive meaning to basketball technology and strategy which could lead basketball activity in to transparent procedure, and thus assure development of basketball activity will fit the demand. International Basketball Association will adjust basketball procedure, asking basketball referees could clear the match rule and apply it with reasonable while taking temporary refereeing, and thus do precise judgment and penalty.

The Manage Skill of Improving Temporary Refereeing. Because of the update of basketball refereeing law and rule, it is asked that referees could enforce management which including as below, first, management of quit rights in a team, when facing sudden situation, they should improve manage level and consciousness, and prevent coach from complaint to record account, as for the might result, referee should prevent timely such as an effect communication that will assure a real and reasonable results. As for breaking-rule phenomenon, referees should take a timely and reasonable judgment to control the whole match, being calamity and try to decrease the conflicts ${ }^{\text {[11] }}$. In basketball match, there is one thing also need to be attention that every operation should under the rules, no matter strategy applying or technology improving, all need to follow the rules. Referees not only need to take related basketball strategy learning but also improve their own basketball technology, promoting recognize of strategies thus they could find that whether the operation of technique movements fit the actual demand or not. They also need to be ready with temporary refereeing and thus could offend, thus they could assure their refereeing technology is improving, and they could push basketball activity with fair and reasonable ${ }^{[12]}$.

\section{Summary}

At present, among college students group, basketball activity has been an essential content, no matter from entertaining aspect or educational development that influence of basketball is grand. In recent development, high school has been paid more and more attention to related content of basketball activity, and because it influenced by various factors, basketball refereeing in high school still has many issues which will affect the development of basketball activity in some degree, and 
thus, they need to seek for effect strategy with positive and complete it, improving basketball refereeing and lead basketball career to healthy development.

\section{References}

[1] Shen Fu. Investigation and Analysis of Influencing Factors of College Basketball Referees' on-the-spot Execution Level in Wuhan[J]. Bulletin of Sport Science \& Technology, 2015(1):50-52.

[2]Gao Guanhua. An Analysis of the Factors Affecting the Integrity of College Basketball Referees in China and the Countermeasures for Improvement[D]. Huazhong Normal University, 2013.

[3] Wang An Dachuan, Zhang Jian, Wang Houlei. Study on the Factors Influencing the Basketball Referee's on-the-spot Penalty and the Countermeasures [J]. HU BEI SPORTS SCIENCE, 2016, 35(3):233-235.

[4]Zhu Yan, Tai Zhongfeng, Wu Hongxue. Research on the Current Situation and Countermeasures of Basketball Referees Training for College Students Majoring in Physical Education in Changchun[J]. HU BEI SPORTS SCIENCE, 2014(6):554-557.

[5] Yu Zhongkun. Internal Causes and Countermeasures for Psychological Pressure of Student Basketball Referees[J]. new curriculum •midmonth, 2014(12).

[6] Lu Xinpeng. Reaserch on the Factors Influencing the Basketball Referee's Penalty and the Countermeasures[J].The New Generation, 2017(8).

[7] Zheng Zhipeng. Research on the Current Situation and Countermeasures of College Basketball Referees in Guiyang__ Take Guizhou Normal University as an Example [J]. Contemporary Sports Technology, 2017(33):54-54.

[8] Xiong Hao. Research on the Influencing Factors and Training Strategies of College Basketball Referees' on-the-spot Execution Ability[J]. Sports world (Academic Edition), 2014(5):101-102.

[9] $\mathrm{Xu}$ Yanlin. Factors Affecting the Accuracy of Basketball Referees and Countermeasures_- Take Sports Institution of Chongqing Technology and Business as an Example[J]. Contemporary Sports Technology, 2017, 7(24):230-231.

[10] Pang Qionghao. Factors Affecting Basketball Referee's on-the-spot Penalty and Countermeasures_- Take Shanxi Province as an Example [J]. Business, 2014(33):267-267.

[11] Ye Suying, Chen Quan. Psychological Analysis and Countermeasures of Basketball Referee's Stage Fright in Guangxi Universities_— Take Guanggxi Normal University as an Example [J]. Education Teaching Forum, 2016(9):132-133.

[12] Fan Weibing, Ma Yun. Factors Influencing the Basketball Referees' on-the-spot Penalty in Xinjiang Colleges and Universities and the Countermeasures[J].Contemporary Sports Technology, 2015, 5(19):215-215. 